\title{
Organocatalyzed enantioselective aldol and Henry reactions starting from benzylic alcohols
}

\author{
Juan V. Alegre-Requena, ${ }^{a}$ Eugenia Marqués-López ${ }^{\mathrm{a}}$ and Raquel P. Herrera ${ }^{\mathrm{a} *}$ \\ a Laboratorio de Organocatálisis Asimétrica. Departamento de Química Orgánica. Instituto de Síntesis Química y \\ Catálisis Homogénea (ISQCH) CSIC-Universidad de Zaragoza. C/ Pedro Cerbuna 12, 50009 Zaragoza (Spain). \\ E-mail: raquelph@unizar.es
}

\begin{abstract}
Pioneering aldol and Henry reactions starting from alcohols are described. The aldol reaction has been successfully performed following a one-pot strategy starting from alcohols, while the Henry reaction has been carried out following a sequential protocol for the first time. In both processes, enantiomerically enriched products were obtained with good yields and high enantioselectivities.
\end{abstract}

We have also demonstrated that in reactions sensitive to small amounts of acid the use of alcohols instead of aldehydes could be a good solution for improving the results of these reactions.

Keywords: alcohol; aldehyde; aldol; Henry; $\mathrm{MnO}_{2}$; organocatalysis; one-pot; oxidation.

\section{Introduction}

Many organic reactions that initially start from aldehydes lead to products of biological interest. Among the plethora of reactions that start from aldehydes, the aldo ${ }^{[1]}$ and the Henry reactions ${ }^{[2]}$ are important carbon-carbon bond-forming methods in organic synthesis. ${ }^{[3]}$ These processes represent two potent strategies for the synthesis of valuable $\beta$ hydroxyketones and $\beta$-nitroalcohols providing, after further transformations, efficient access to interesting and highly functionalized intermediates. Both reactions have been developed under many different conditions and using diverse catalytic systems, providing from good-to-excellent enantioselectivities. ${ }^{[4-6]}$

During the development of our previous Henry protocol, ${ }^{17]}$ we realized that the presence of traces of acid in the aldehydes used could inactivate the small amount of catalyst employed $(0.0044 \mathrm{mmol})$. It is well known that traces of acids are generated in aldehydes due to oxidation processes (see the supporting information for images of this process, Figure S1). This could be a serious problem that appears when using diverse aldehydes. In fact, many of these aldehydes that we used were purified before the reactions in order to avoid the inactivation of the catalyst. The influence of different amounts of acids on the reactivity and the enantioselectivity of diverse organocatalytic reactions (e.g., in aminocatalysis) has been also explored by other authors.

Hence, this problem encouraged us to explore the challenge of forming the aldehydes in situ by oxidizing alcohols. In fact, there is a wider variety of alcohols available in comparison with aldehydes, and they are much easier to handle and work with. For this reason, it seems evident that the use of alcohols in organic processes instead of aldehydes would significantly increase the versatility of the reactions, especially when the aldehydes are unstable or difficult to handle. ${ }^{[8]}$ Therefore, the exploration of new asymmetric catalytic methodologies of reactions where carbonyl compounds are used as starting materials is still important for an efficient construction of interesting building blocks. Consequently, the development of Henry and aldol reactions starting from alcohols would open a new area of research in the progress of these interesting reactions (Scheme 1).

\section{Previous studies}

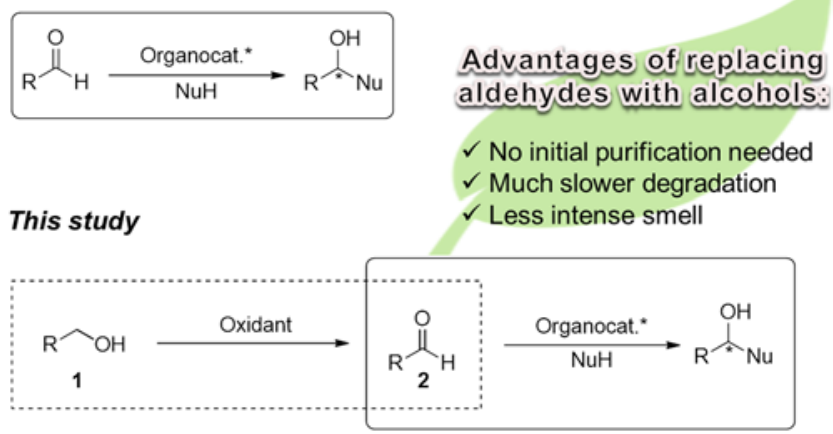

Scheme 1. The goal of this research: developing aldol and Henry reactions starting from alcohols. 
The oxidation of alcohols to aldehydes or ketones is an important process in organic synthesis and several methods have been successfully developed to accomplish this transformation, ${ }^{[9]}$ like for example, using organocatalytic procedures. ${ }^{[10]}$ However, it is much rarer to find examples where the carbonyl group generated in the oxidation is involved in a subsequent asymmetric catalytic process. In fact, there are only a few studies on this and in all of them, the second reactions were carried out using prolinederived catalysts. ${ }^{[1]}$ Therefore, the development of new oxidative processes of alcohols to generate aldehydes involved in subsequent organocatalytic protocols is highly desirable.

\section{Results and Discussion}

Among the different oxidants analyzed in the literature (IBX, TEMPO, Swern oxidant, $\mathrm{MnO}_{2}$, etc.), we realized that the mildest and most efficient one for our aim was $\mathrm{MnO}_{2} \cdot{ }^{[12]}$ Moreover, the use of the other oxidants mentioned would lead to the generation of acids during the oxidation reactions, which could inhibit the successive catalytic reactions in this investigation. In order to demonstrate our hypothesis, we first explored the aldol reaction depicted in Table 1. ${ }^{[13]}$ This example represents the first one-pot aldol reaction starting from alcohols and catalyzed by a cinchona-derived primary amine. ${ }^{[14]}$

As reported in Table 1, it was possible to successfully oxidize alcohols in different solvents. Interestingly, the final product 5a was produced with consistently better results when alcohol 1a was used instead of aldehyde 2a. In the original study starting from aldehydes, the authors noticed that when the amount of acid was higher than $15 \%$, the yield of the reactions dropped. ${ }^{[13]}$ Therefore, the decrease observed in the yield when 2a is used could be mostly caused by the residual amounts of acid that this aldehyde generates through its oxidation over time. It is remarkable that, in all examples, the in situ generated aldehyde was used without having been purified, following a one-pot procedure.

Table 1. Screening of the one-pot cinchona-catalyzed aldol reaction starting from alcohol 1a or aldehyde 2a in different solvents. ${ }^{[\mathrm{a}]}$

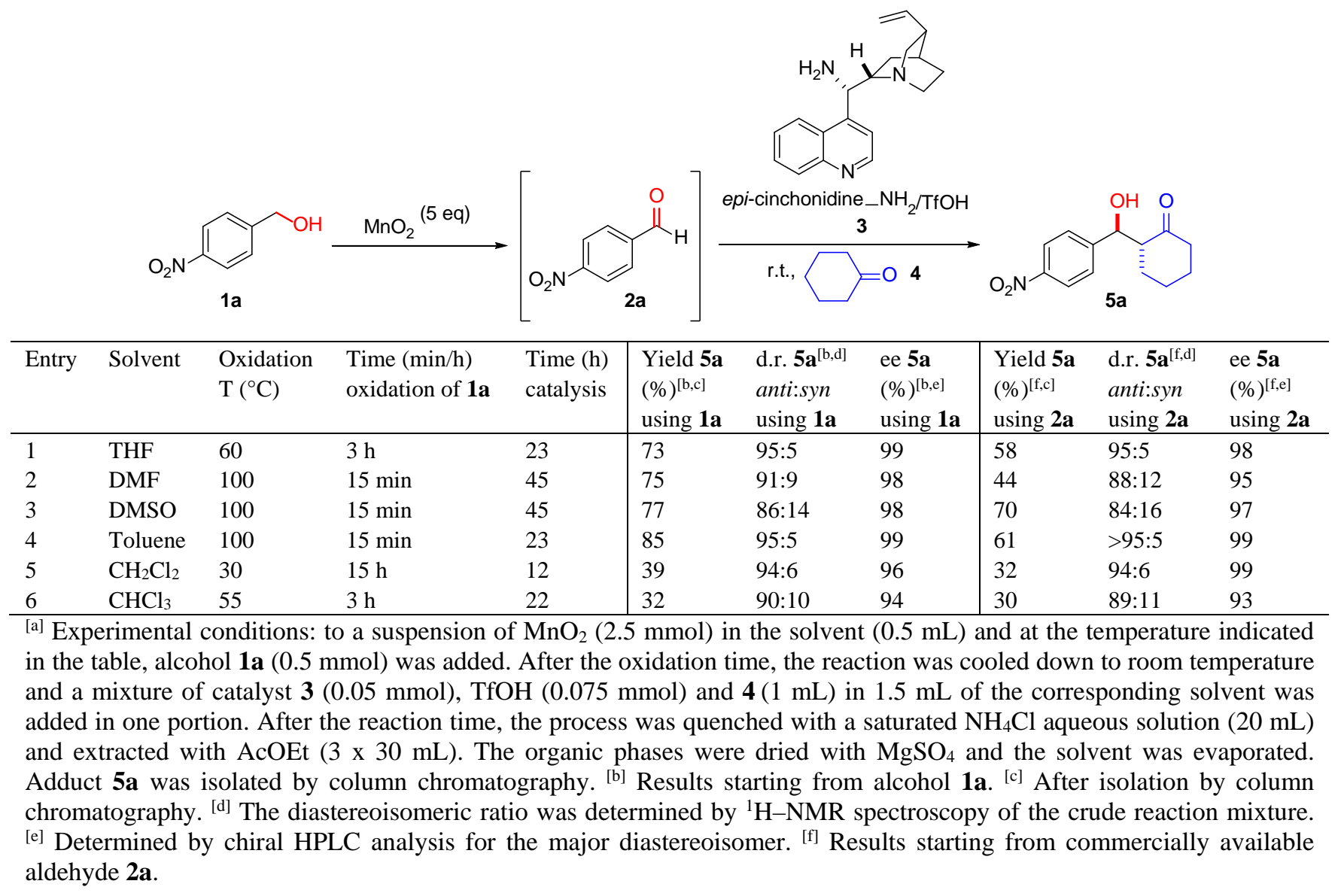

We then explored the efficiency of the one-pot protocol using a variety of alcohols (Table 2 and Scheme S1) under the best reaction conditions found during the screening (Table 1, entry 4). As depicted in Table 2, the aldol reaction led to the desired $\beta$ hydroxyketones $\mathbf{5}$ in good yields and excellent enantioselectivities (up to $99 \%$ ee). The reactivity of 
the process depends on the electronic effects of the aromatic rings, as better yields are obtained with electron-withdrawing substituents in shorter reaction times. However, these electronic effects are not correlated with the enantioselectivity of the process.

Table 2 Scope of the one-pot cinchona-catalyzed aldol reaction starting from alcohols $\mathbf{1 a - g}$. $^{\text {a] }}$

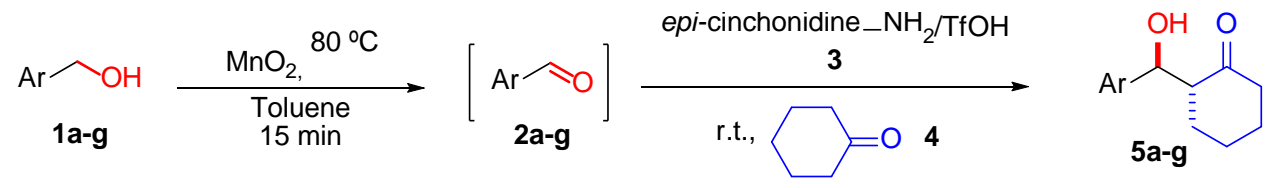

\begin{tabular}{|c|c|c|c|c|c|}
\hline Entry & $\operatorname{Ar}(\mathbf{1 a}-\mathbf{h})$ & $\begin{array}{l}\text { Time (h) } \\
\text { catalysis }\end{array}$ & Yield $5(\%)^{[b]}$ & $\begin{array}{l}\text { d.r. } 5^{[\mathrm{c}]} \\
\text { anti:syn }\end{array}$ & ee $5(\%)^{[\mathrm{d}]}$ \\
\hline 1 & 4-NO $\mathrm{NO}_{2} \mathrm{Ph}(\mathbf{1 a})$ & 17 & 83 & 93:7 & 99 \\
\hline 2 & $3-\mathrm{NO}_{2} \mathrm{Ph}(\mathbf{1 b})$ & 17 & 71 & $92: 8$ & 99 \\
\hline 3 & 4-CNPh (1c) & 18 & 75 & 91:9 & 98 \\
\hline 4 & 4-ClPh (1d) & 63 & 76 & $92: 8$ & 97 \\
\hline 5 & 4-BrPh (1e) & 64 & 70 & $90: 10$ & 97 \\
\hline 6 & $\mathrm{Ph}$ (1f) & 100 & 53 & $90: 10$ & $>99$ \\
\hline 7 & 2-furyl (1g) & 101 & 71 & $75: 25$ & 93 \\
\hline
\end{tabular}

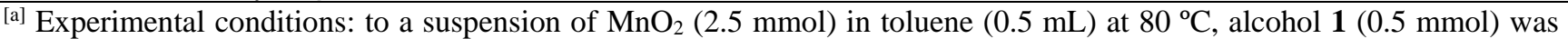
added. After the oxidation time, the reaction was cooled down to room temperature and a mixture of catalyst 3 (0.05 $\mathrm{mmol})$, TfOH $(0.075 \mathrm{mmol})$ and $\mathbf{4}(1.5 \mathrm{~mL})$ was added in one portion. After the reaction time, the process was quenched with a saturated $\mathrm{NH}_{4} \mathrm{Cl}$ aqueous solution $(20 \mathrm{~mL})$ and extracted with AcOEt $(3 \times 30 \mathrm{~mL})$. The organic phases were dried with $\mathrm{MgSO}_{4}$ and the solvent was evaporated. Adduct 5 was isolated by column chromatography. ${ }^{[b]}$ After isolation by column chromatography. ${ }^{[c]}$ The diastereoisomeric ratio was determined by ${ }^{1} \mathrm{H}-\mathrm{NMR}$ spectroscopy of the crude reaction mixture. ${ }^{[\mathrm{d}]}$ Determined by chiral HPLC analysis for the anti diastereoisomer.

Recently, we have developed a trifunctional squaramide catalyst that promotes the Henry reaction through a multidentate activation. ${ }^{[7]}$ Encouraged by the results obtained for the aldol reaction, we envisioned to apply this idea (Scheme 1) also to that reaction.

Initially, the screening of the oxidation reaction using alcohol $\mathbf{1 f}$ (reported in Table S1) was conducted in $\mathrm{CH}_{3} \mathrm{CN}$, since the following catalytic Henry step was successfully performed in mixtures of this solvent with $\mathrm{MeNO}_{2}$. Compound 1f reacted completely in the oxidative process using 5 equivalents of $\mathrm{MnO}_{2}$ at $80{ }^{\circ} \mathrm{C}$ (Table S1, entry 6). Interestingly, traces of acid or other by-products from alcohol 1f were not detected by ${ }^{1} \mathrm{H}-\mathrm{NMR}$ during the process even after long reaction times, supporting our initial aim.

Then, the time necessary for the total conversion of each alcohol $\mathbf{1}$ in its corresponding aldehyde $\mathbf{2}$ was analyzed (Scheme 2). We observed that alcohols with aromatic rings that bear electron-withdrawing groups (alcohols $\mathbf{1 a}-\mathbf{e}, \mathbf{j}$ ) required longer oxidation times in comparison with alcohols $\mathbf{1 f}-\mathbf{i}$.

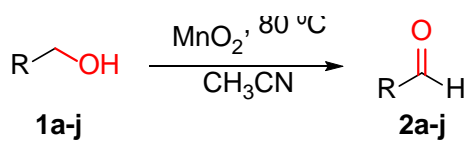<smiles>O=[N+]([O-])c1ccc(CO)cc1</smiles><smiles>N#Cc1ccc(CO)cc1</smiles><smiles>OCc1ccc(Cl)cc1</smiles><smiles>OCc1ccc(Br)cc1</smiles>

$1 \mathrm{a}$
$13 \mathrm{~h}$

$$
13 \mathrm{~h}
$$$$
\text { 1c }
$$$$
13 \mathrm{~h}
$$<smiles>OCc1ccccc1</smiles><smiles>Cc1ccc(CO)cc1</smiles><smiles>OCc1cccc2ccccc12</smiles><smiles>OCc1cccc(Cl)c1</smiles>

$\underset{4 \mathrm{~h}}{\mathbf{1 f}}$
$1 \mathrm{~h}$
$4 \mathrm{~h}$
$1 \mathrm{j}$

Scheme 2. Oxidation of alcohols 1 . Reaction conditions: 1 $\mathrm{mmol}$ of 1 and $5 \mathrm{mmol}$ of $\mathrm{MnO}_{2}$ in $1 \mathrm{~mL}$ of $\mathrm{CH}_{3} \mathrm{CN}$ at 80 ${ }^{\circ} \mathrm{C}$.

With the optimal reaction conditions in hand for the oxidation step (Scheme 2), we firstly analyzed the catalytic Henry system following a one-pot protocol as shown in Scheme 3. 


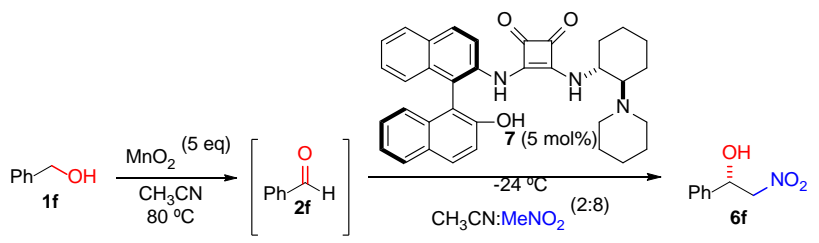

Scheme 3. One-pot Henry reaction.

Unfortunately, product 6f was not observed after 4 days of reaction. This fact made us think that some of the reagents or by-products that come from the oxidation step were inactivating the subsequent Henry process. To avoid these impurities, the solid generated during this step was filtered and the catalytic reaction was performed in a sequential manner. Then, $100 \mu \mathrm{L}$ of the filtered solution, without purification of the in situ generated aldehyde, were added over a mixture of catalyst 7 and $\mathrm{MeNO}_{2}$. The process worked well in terms of enantioselectivity (83\% ee) and reactivity (53\% yield) (Table 3 , entry 6 ) and, again, better yields were found when alcohol 1f was employed in comparison with the outcomes observed when using aldehyde $\mathbf{2 f}$ (35\% yield).

The efficiency of this protocol was further studied for a range of different alcohols $(\mathbf{1} \mathbf{a}-\mathbf{j})$ and the results were compared to those obtained when the initial reagents were the corresponding commercially available aldehydes (2a-j) (Table 3).

Table 3. Scope of the squaramide-catalyzed Henry reaction starting from alcohols $\mathbf{1 a}-\mathbf{j}$ and from aldehydes $\mathbf{2 a - \mathbf { j }}$ under the same reaction conditions. ${ }^{\text {[a] }}$

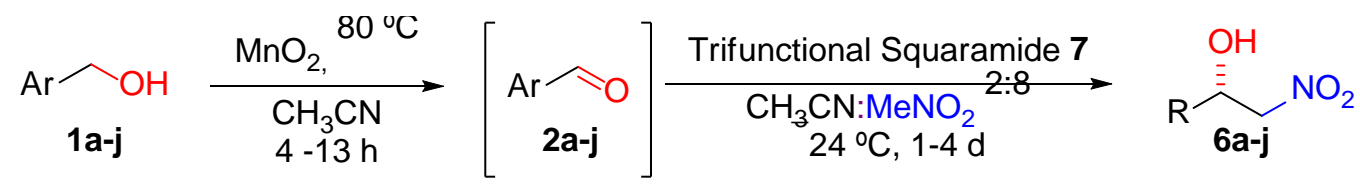

\begin{tabular}{|c|c|c|c|c|c|c|}
\hline Entry & $\bar{R}$ & Time (h) & $\begin{array}{l}\text { Yield } 6(\%) \\
\text { using } \mathbf{1}^{[\mathrm{b}, \mathrm{c}]}\end{array}$ & $\begin{array}{l}\text { ee } \mathbf{6}(\%) \\
\text { using } \mathbf{1}^{[\mathrm{b}, \mathrm{d}]}\end{array}$ & $\begin{array}{l}\text { Yield } 6 \text { (\%) } \\
\text { using } 2^{[\mathrm{c}, \mathrm{e}]}\end{array}$ & $\begin{array}{l}\text { ee } \mathbf{6}(\%) \\
\text { using } 2^{[\mathrm{d}, \mathrm{e}]}\end{array}$ \\
\hline 1 & 4-NO ${ }_{2} \mathrm{Ph}(\mathbf{1 a})$ & 23 & $>95$ & 79 & $>95$ & 80 \\
\hline 2 & $3-\mathrm{NO}_{2} \mathrm{Ph}(\mathbf{1 b})$ & 23 & $>95$ & 93 & $>95$ & 93 \\
\hline 3 & 4-CNPh (1c) & 23 & 76 & 81 & $>95$ & 80 \\
\hline 4 & 4-ClPh (1d) & 96 & 89 & 83 & 73 & 85 \\
\hline 5 & 4-BrPh (1e) & 96 & 86 & 84 & 33 & 85 \\
\hline 6 & $\mathrm{Ph}$ (1f) & 69 & 53 & 83 & 35 & 85 \\
\hline 7 & 2-furyl (1g) & 93 & 69 & 92 & 26 & 90 \\
\hline 8 & 4-MePh (1h) & 93 & 37 & 86 & n.r..$^{f}$ & n.d. ${ }^{g}$ \\
\hline 9 & 1-Naphthyl (1i) & 93 & 66 & 80 & n.r. ${ }^{f}$ & n.d. ${ }^{g}$ \\
\hline 10 & 3-ClPh (1j) & 96 & 87 & 83 & n.r. $f$ & n.d..$^{g}$ \\
\hline
\end{tabular}

${ }^{\text {[a] }}$ Experimental conditions: to a suspension of $\mathrm{MnO}_{2}(5 \mathrm{mmol})$ in $\mathrm{CH}_{3} \mathrm{CN}(1 \mathrm{~mL})$ at $80{ }^{\circ} \mathrm{C}$, alcohol 1 (1 mmol) was added. After the oxidation time (Scheme 2), the reaction was cooled down to room temperature and the suspension was filtered using a HPLC filter of $0.22 \mu \mathrm{m}$. Then, $0.1 \mathrm{~mL}$ of the solution filtrated were collected and added to a solution of catalyst 7 $(0.005 \mathrm{mmol})$ in $\mathrm{MeNO}_{2}(0.4 \mathrm{~mL})$ at $-24^{\circ} \mathrm{C}$. After the reaction time, adduct 6 was isolated by column chromatography. ${ }^{\text {b] }}$ Results starting from alcohols 1. ${ }^{[c]}$ After isolation by column chromatography. ${ }^{[\mathrm{d}]}$ Determined by chiral HPLC analysis. ${ }^{[\mathrm{e}]}$ Results starting from commercially available aldehydes $2 .{ }^{[\mathrm{f}]}$ No reaction observed after 3 days. ${ }^{[\mathrm{g}]}$ Not determined.

As shown in Table 3, the Henry reaction took place rendering the desired $\beta$-nitroalcohols 6 in good to excellent yields (up to >95\%) and high enantioselectivities (up to $93 \%$ ee) with very clean reaction crudes. The enantioselectivity did not depend on the electronic effects of the alcohols. However, the reactivity is probably correlated with the electronic effects of the aromatic rings since the reagents with an electron-withdrawing group in the aromatic ring exhibited more reactivity (Table 3 , entries $1-5$ and 10). Although the enantiomeric excesses observed when using alcohols are practically identical compared with those obtained when aldehydes are employed, the reactivity is better in almost all the cases (see 1d-j). It is remarkable that in the reactions using commercially available aldehydes $\mathbf{2 h}-\mathbf{j}$ without previous purification no products were formed. This occurs because the presence of traces of acid in these aldehydes inactivates the small amount of catalyst used in the process. In fact, in our previous research, ${ }^{[7]}$ many of the aldehydes required a preliminary treatment in order to remove the acids and avoid such inactivation. In some cases, a few minutes after purifying the aldehydes, the generation of acid was observed in the aldehydes.

\section{Conclusion}

In summary, we have successfully developed the first asymmetric catalytic aldol and Henry reactions starting from alcohols $\mathbf{1}$. The combination of an oxidation and a successive aldol or Henry protocol produced $\beta$-hydroxyketones 5 and $\beta$-nitroalcohols $\mathbf{6}$, 
respectively, with very good results. It was found that, in some cases, the same Henry reactions using commercially available aldehydes 2 did not work after four days. Moreover, we have proven that the oxidation step can be carried out for diverse substituted aromatic alcohols using different solvents without impairing in the results of the reaction. Our protocol demonstrates that using alcohols leads in general, to better results than using aldehydes, especially in cases where aldehydes oxidized easily or are difficult to handle. The procedure described herein could open new opportunities and could be applied to other reactions which start from aldehydes. Further research on the efficacy of this organocatalytic approach in other asymmetric reactions is ongoing in our lab in order to extend this idea.

\section{Experimental Section}

General experimental methods. Purification of reaction products was carried out by column chromatography using silical-gel $(0.063-0.200 \mathrm{~mm})$. Analytical thin layer chromatography was performed on $0.25 \mathrm{~mm}$ silical gel 60F plates. ${ }^{1} \mathrm{H}$-NMR spectra were recorded at $300 \mathrm{MHz} ;{ }^{13} \mathrm{C}$ APT-NMR spectra were recorded at $75 \mathrm{MHz}$; $\mathrm{CDCl}_{3}$ was used as the deuterated solvents. Chemical shifts were reported in the $\delta$ scale relative to residual $\mathrm{CHCl}_{3}(7.28$ $\mathrm{ppm})$ for ${ }^{1} \mathrm{H}-\mathrm{NMR}$ and to the central line of $\mathrm{CDCl}_{3}$ (77 ppm) for ${ }^{13}$ C-APT-NMR.

Materials. Spectral data for $5 \mathbf{a}-\mathbf{g},{ }^{[13]} \mathbf{6 a},{ }^{[15]} \mathbf{6 b},{ }^{[16]} \mathbf{6 c},{ }^{[17]}$ $\mathbf{6 d})^{[15]} \mathbf{6 e},^{[17]} \mathbf{6 f},{ }^{[17]} \mathbf{6 g},{ }^{[17]} \mathbf{6 h},{ }^{[18]} \quad \mathbf{6 i},,^{118]}$ and $\mathbf{6 j} \mathbf{j}^{[18]}$ are consistent with values previously reported in the literature. See supporting information for all spectra and HPLC chromatograms.

\section{Representative procedure for the organocatalyzed aldol reaction starting from alcohols.}

To a suspension of $\mathrm{MnO}_{2}(2.5 \mathrm{mmol})$ in toluene $(0.5 \mathrm{~mL})$ at $80{ }^{\circ} \mathrm{C}$, alcohol 1a-g $(0.5 \mathrm{mmol})$ was added. After the oxidation time, the reaction was cooled down to room temperature and a mixture of catalyst $3(0.05 \mathrm{mmol})$, TfOH $(0.075 \mathrm{mmol})$ and $4(1.5 \mathrm{~mL})$ was added in one portion. After the reaction time (Table 2), the process was quenched with a saturated $\mathrm{NH}_{4} \mathrm{Cl}$ aqueous solution (20 $\mathrm{mL})$ and extracted with AcOEt $(3 \times 30 \mathrm{~mL})$. The organic phases were dried with $\mathrm{MgSO}_{4}$ and the solvent was evaporated. Adduct $\mathbf{5}$ was isolated by column chromatography.

Representative procedure for the organocatalyzed Henry reaction starting from alcohols.

To a suspension of $\mathrm{MnO}_{2}(5 \mathrm{mmol})$ in $\mathrm{CH}_{3} \mathrm{CN}(1 \mathrm{~mL})$ at $80{ }^{\circ} \mathrm{C}$, alcohol 1a-j $(1 \mathrm{mmol})$ was added. After the oxidation time (Scheme 2), the reaction was cooled down to room temperature and the suspension was filtered using a HPLC filter of $0.22 \mu \mathrm{m}$. Then, $0.1 \mathrm{~mL}$ of the solution filtrated were collected and added to a solution of catalyst $7(0.005 \mathrm{mmol})$ in $\mathrm{MeNO}_{2}(0.4 \mathrm{~mL})$ at $-24{ }^{\circ} \mathrm{C}$. After the reaction time (Tabe 3), adduct 6 was isolated by flash chromatography.

\section{Acknowledgements}

We thank the Government of Aragon DGA (Research Group E104) for financial support of our research. J.V.A.-R. thanks the DGA for a predoctoral contract. The authors thank Leah C. Weatherman for her help during the text editing process.

\section{References}

[1] a) C. A. Wurtz, Bull. Soc. Chim. Fr. 1872, 17, 436-442; b) C. A. Wurtz, J. Prakt. Chem. 1872, 5, 457-464.

[2] L. Henry, C. R. Hebd. Séances Acad. Sci. 1895, 120, 1265-1268.

[3] F. A. Luzzio, Tetrahedron 2001, 57, 915-945.

[4] a) R. Mahrwald (Ed.) Modern aldol reaction. WileyVCH: Weinheim, 2004; b) C. Palomo, M. Oiarbide, J. M. García, Chem. Eur. J. 2002, 8, 36-44; c) B. M. Trost, C. S. Brindle, Chem. Soc. Rev. 2010, 39, 1600-1632; d) M. Bhanushali, C.-G. Zhao, Synthesis 2011, 18151830; e) V. Bisai, A. Bisai, V. K. Singh, Tetrahedron 2012, 68, 4541-4580; f) M. M. Heravi, S. Asadi, Tetrahedron: Asymmetry 2012, 23, 1431-1465; g) M. M. Heravi, V. Zadsirjan, M. Dehghani, N. Hosseintash, Tetrahedron: Asymmetry 2017, 28, 587-707.

[5] J. Boruwa, N. Gogoi, P. P. Saikia, N. C. Barua, Tetrahedron: Asymmetry 2006, 17, 3315-3326.

[6] a) C. Palomo, M. Oiarbide, A. Mielgo, Angew. Chem. Int. Ed. 2004, 43, 5442-5444; b) C. Palomo, M. Oiarbide, A. Laso, Eur. J. Org. Chem. 2007, 25612576; c) Y. Alvarez-Casao, E. Marqués-López, R. P. Herrera, Symmetry 2011, 3, 220-245.

[7] a) J. V. Alegre-Requena, E. Marqués-López, R. P. Herrera, Adv. Synth. Catal. 2016, 358, 1801-1809. Highlighted in Synfacts 2016, 12, 743; b) J. V. AlegreRequena, E. Marqués-López, R. P. Herrera, ACS Catal. 2017, 7, 6430-6439; c) J. V. Alegre-Requena, E. Marqués-López, R. P. Herrera, Chem. Eur. J. 2017 DOI: $10.1002 /$ chem.201702841.

[8] a) R. J. K. Taylor, M. Reid, J. Foot, S. A. Raw, Acc. Chem. Res. 2005, 38, 851-869; b) K. Ekoue-Kovi, C. Wolf, Chem. Eur. J. 2008, 14, 6302-6315.

[9] G. Tojo, M. Fernandez (Eds.) Oxidation of alcohols to aldehydes and ketones. Springer Science: New York, 2006.

[10] For a few examples, see: a) C. B. Tripathi, S. Mukherjee, J. Org. Chem. 2012, 77, 1592-1598; b) M. Hayashi, M. Shibuya, Y. Iwabuchi, J. Org. Chem. 2012, 77, 3005-3009; c) A. Abramovich, H. Toledo, E. Pisarevsky, A. M. Szpilman, Synlett 2012, 23, 22612265; d) A. Al-Hunaiti, M. Räisänen, P. Pihko, M. Leskelä, T. Repo, Eur. J. Org. Chem. 2014, 6141-6144; e) X. Chen, Y. Zhang, H. Wan, W. Wang, S. Zhang, Chem. Commun. 2016, 52, 3532-3535.

[11] For the scarce examples of oxidation of alcohols in iminium catalysis, see: a) A. Quintard, A. Alexakis, C. Mazet, Angew. Chem. Int. Ed. 2011, 50, 2354-2358; b) M. Rueping, H. Sundén, E. Sugiono, Chem. Eur. J. 
2012, 18, 3649-3653; c) M. Rueping, H. Sundén, L. Hubener, E. Sugiono, Chem. Commun. 2012, 48, 22012203; d) C. W. Suh, D. Y. Kim, Org. Lett. 2014, 16, 5374-5377; e) N. K. Rana, H. Joshi, R. K. Jha, V. K. Singh, Chem. Eur. J. 2017, 23, 2040-2043.

[12] $\mathrm{MnO}_{2}$ could be passivated over time with moisture from the air. Therefore, activated $\mathrm{MnO}_{2}$ was employed in this study from different commercial sources (85$90 \%$ purity).

[13] B.-L. Zheng, Q.-Z. Liu, C.-S. Guo, X.-L. Wang, L. He, Org. Biomol. Chem. 2007, 5, 2913-2915.

[14] For selected reviews concerning primary amine catalysis, see: a) F. Peng, Z. Shao, J. Mol. Catal. A 2008, 285, 1-13; b) L. W. Wu, Y. Lu, Org. Biomol. Chem. 2008, 6, 2047-2053; c) L.-W. Xu, J. Luo, Y. Lu,
Chem. Commun. 2009, 1807-1821; d) Y.-C. Chen, Synlett 2008, 1919-1930; e) U. V. S. Reddy, M. Chennapuram, C. Seki, E. Kwon, Y. Okuyama, H. Nakano, Eur. J. Org. Chem. 2016, 4124-4143.

[15] M. Steurer, C. Bolm, J. Org. Chem. 2010, 75, 33013310.

[16] S. Kitagaki, T. Ueda, C. Mukai, Chem. Commun. 2013, 49, 4030-4032.

[17] C. V.-L. Bray, F. Jiang, X.-F. Wu, J.-B. Sortais, C. Darcel, Tetrahedron Lett. 2010, 51, 4555-4557.

[18] B. Zheng, M. Wang, Z. Li, Q. Bian, J. Mao, S. Li, S. Liu, M. Wang, J. Zhong, H. Guo, Tetrahedron: Asymmetry 2011, 22, 1156-1160. 
